\title{
laboratorio paulista de biología
}

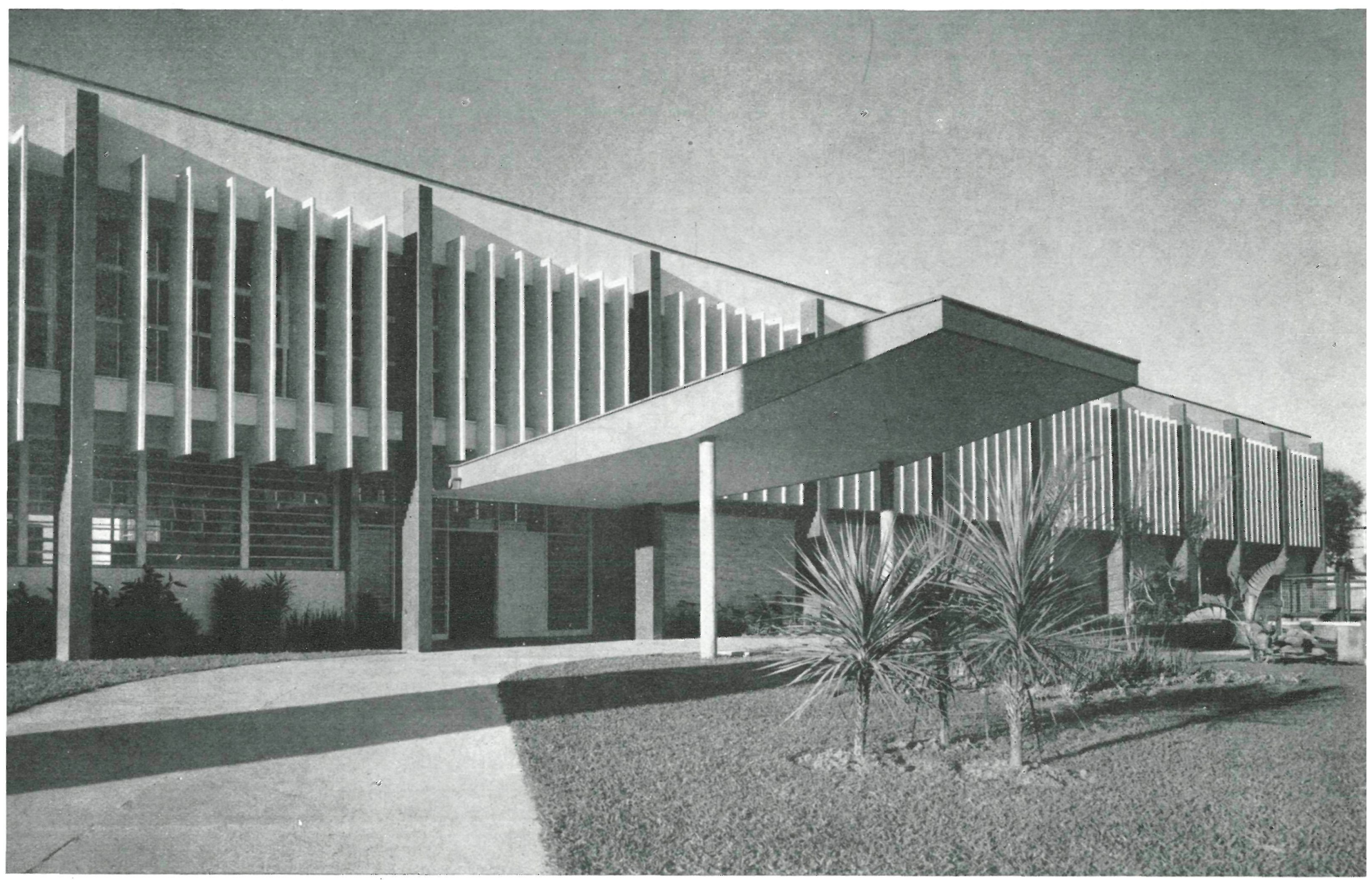

RINO LEVI, arquitecto ROBERTO CERQUEIRA CESAR Y LUIS ROBERTO CARVALHO FRANCO, arquitectos asociados

Proyecto 1956 - Acabado en 1959

$133-14$

Este moderno conjunto industrial está situado en la calle María Cándida, de la ciudad de Sao Paulo, en un amplio solar de casi dos hectáreas de extensión. Está destinado a la fabricación de productos farmacéuticos, principalmente de inyectables.

El complejo construido comprende las siguientes secciones: administración, almacén de materias primas, laboratorios químicos, fabricación y oficinas.

Para conseguir un mejor funcionamiento de este complejo se adoptó la solución de bloques exentos con el fin de separar claramente las diversas secciones. 


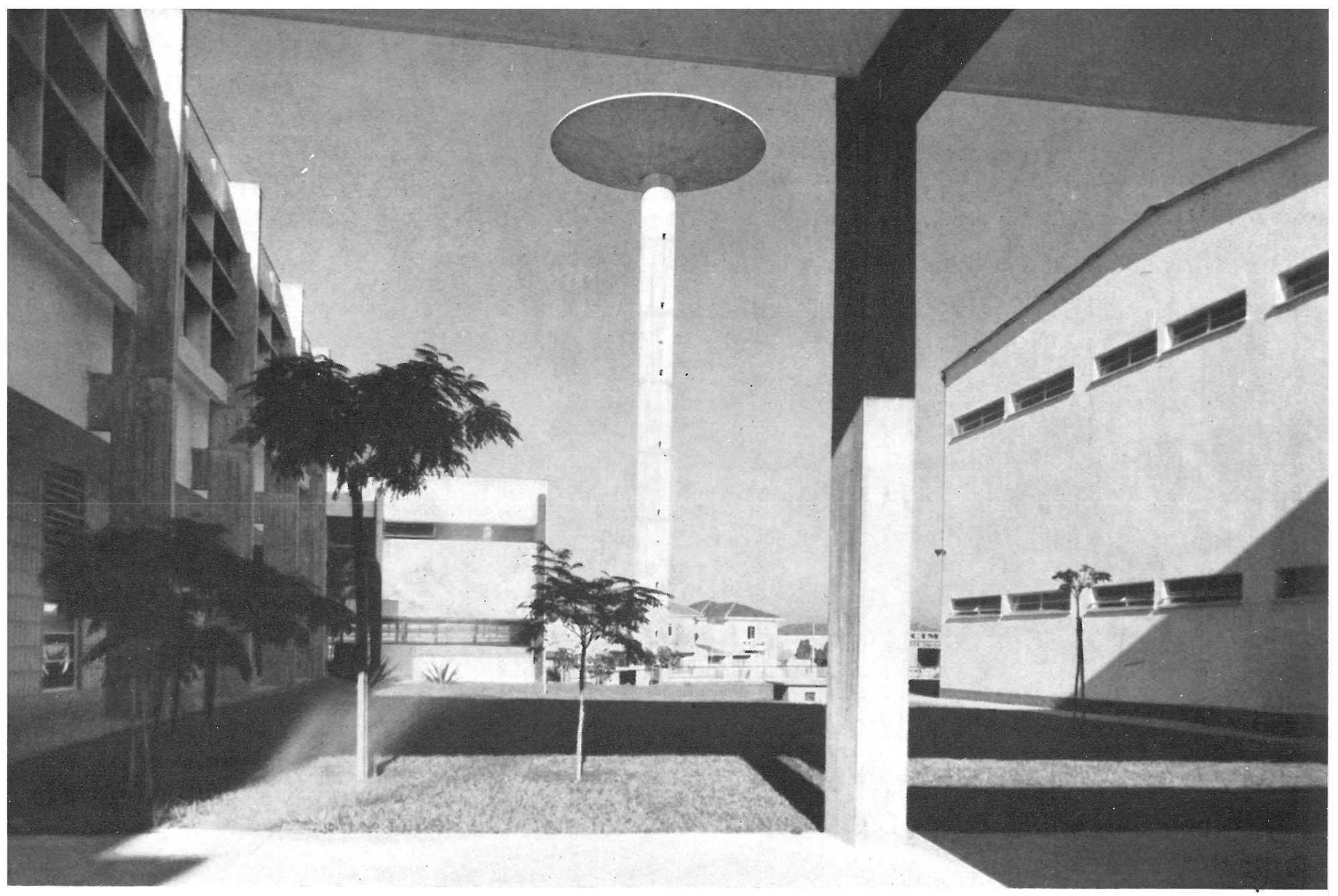

Resultaron así cuatro edificios de dos plantas cada uno, unidos entre sí, y cada cual con características propias bien diferenciadas; en uno de ellos fueron agrupadas las secciones de almacenaje y despacho, debido a la afinidad de sus características constructivas. En los otros tres están situadas las restantes secciones.

Los edificios, rodeados de jardines, han sido distribuidos en el terreno teniendo en cuenta las características topográficas del mismo. Así, los camiones pueden llegar hasta las mismas puertas del almacén, a través de una rampa lateral construida en el terreno aprovechando el desnivel existente; mientras que en el sótano se ha construido una amplia nave, que se utiliza como garaje para los camiones y para taller mecánico de reparaciones.

Sobre todo este conjunto de edificaciones destaca notablemente, en altura, un depósito de agua construido con hormigón armado y que tiene un diámetro de $13 \mathrm{~m}$, altura de $36 \mathrm{~m}$ y capacidad para 100.000 litros. 
Las instalaciones para los obreros constan de la siguientes secciones:

1) Consultorio médico y guardería infantil, situados en la planta baja del edificio destinado a la administración.

2) Estacionamiento para bicicletas, vestuarios y comedores, instalados en el piso inferior del edificio destinado a albergar los laboratorios químicos.

3) Patio con jardín dedicado al recreo durante el tiempo libre que se concede antes de ir a comer. En este patio se han construido dos refugios contra la lluvia, de hormigón armado, con forma de sombrilla y con un diámetro en su parte superior de 12 metros.
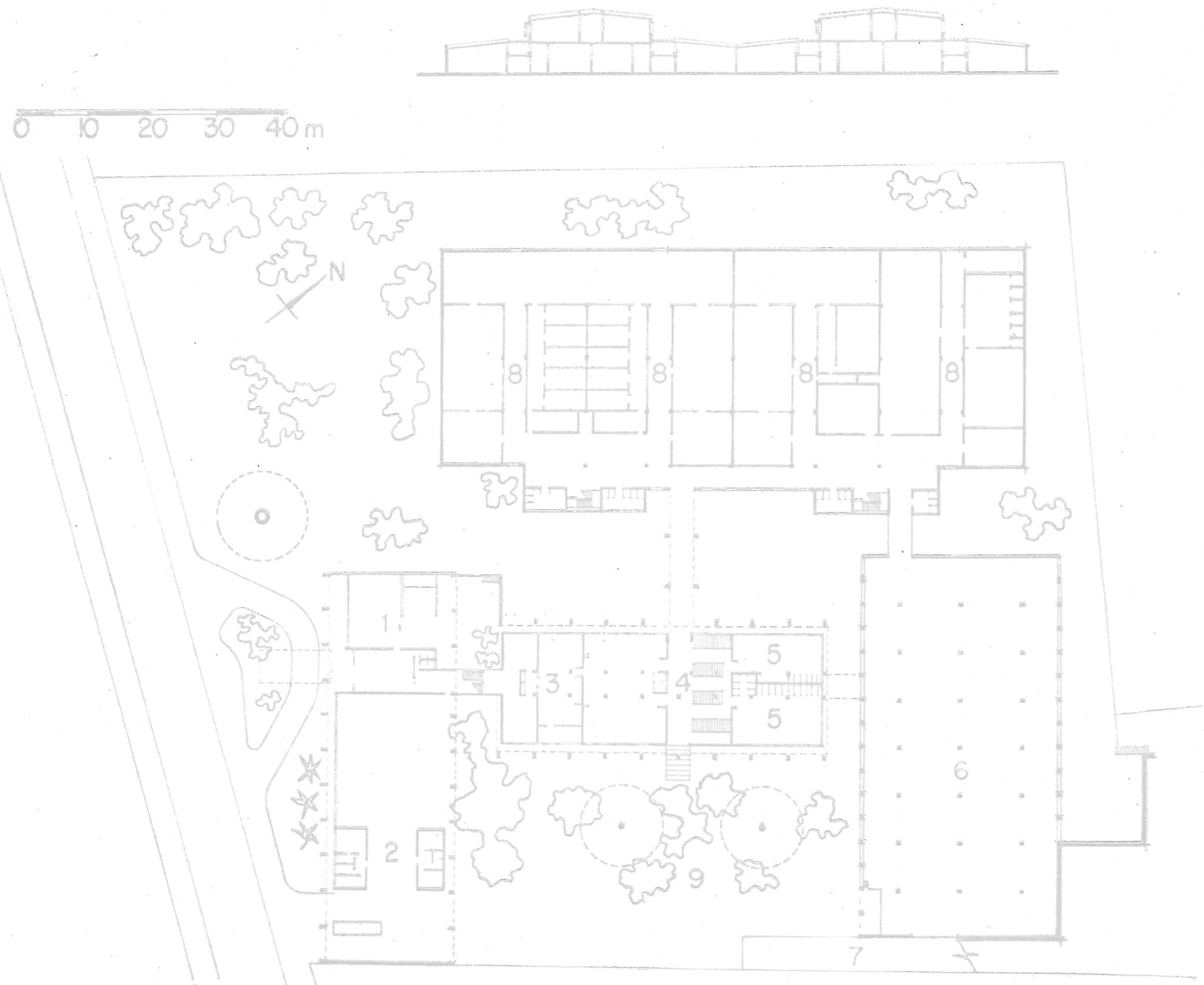
Se han tomado medidas especiales para conseguir una perfecta regulación de la iluminación natural y, para ello, se ha modulado todo el proyecto-si bien han sido tomadọs diferentes módulos para cumplir mejor los requisitos exigidos por cada edificio-, consiguiéndose así una iluminación difusa y dosificada. Se han empleado brise-soleil móviles y fijos, siendo los primeros de aluminio y los segundos a base de placas prefabricadas de hormigón y fibro-cemento recubiertas por una piel de pintura blanca cuyo elemento principal es el caucho.

La estructura es de hormigón armado y presenta características propias y particulares en cada bloque, de acuerdo con la función a que ha sido destinada.

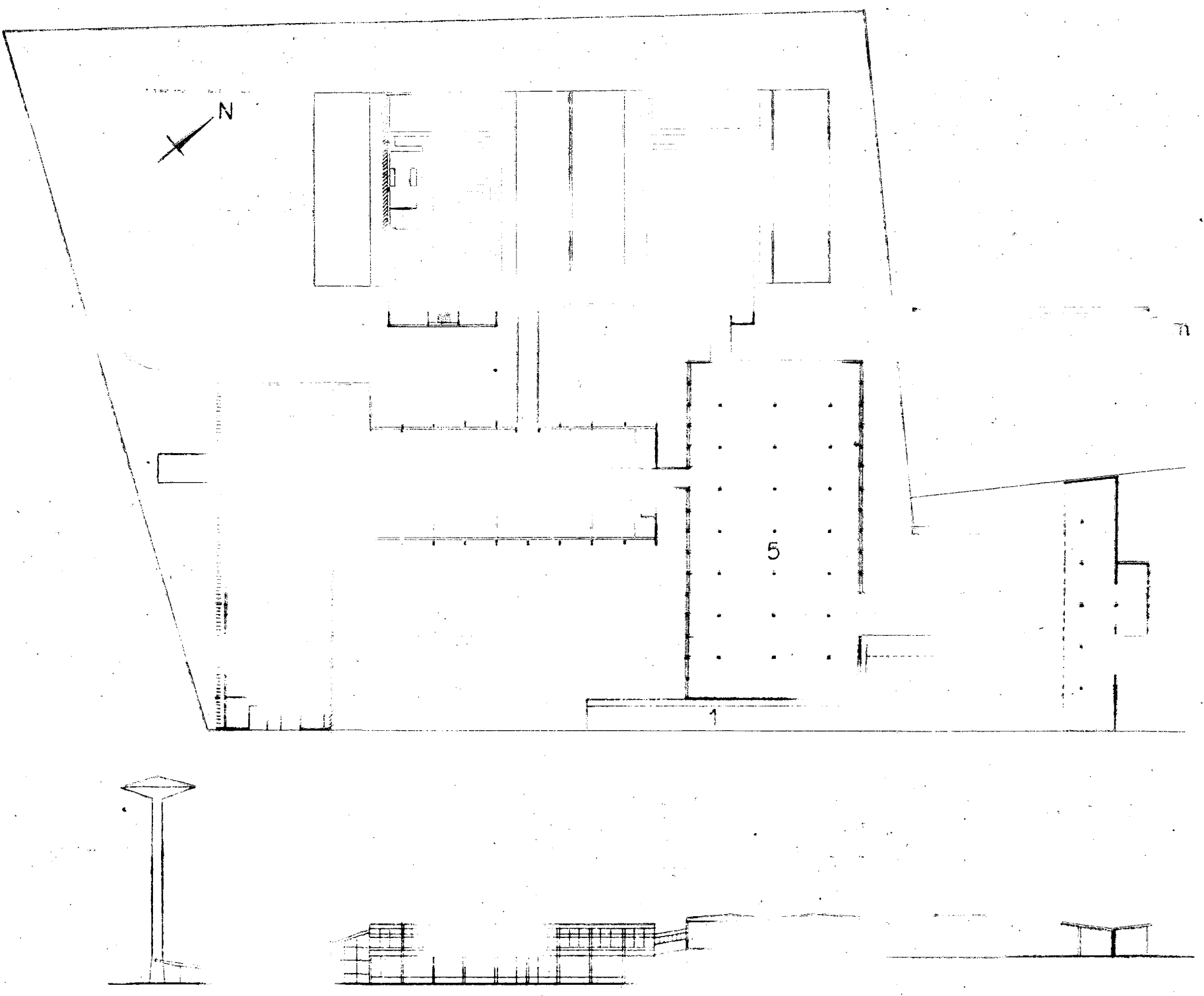

planta primera y seceión
1. Rampa-2. Fábrica-3. Administración:-4. Laboratorio quimico y preparación -5. Depósito de materias primas:-6. Depósito
de materias inflamables.-7. Depósito de agua. 

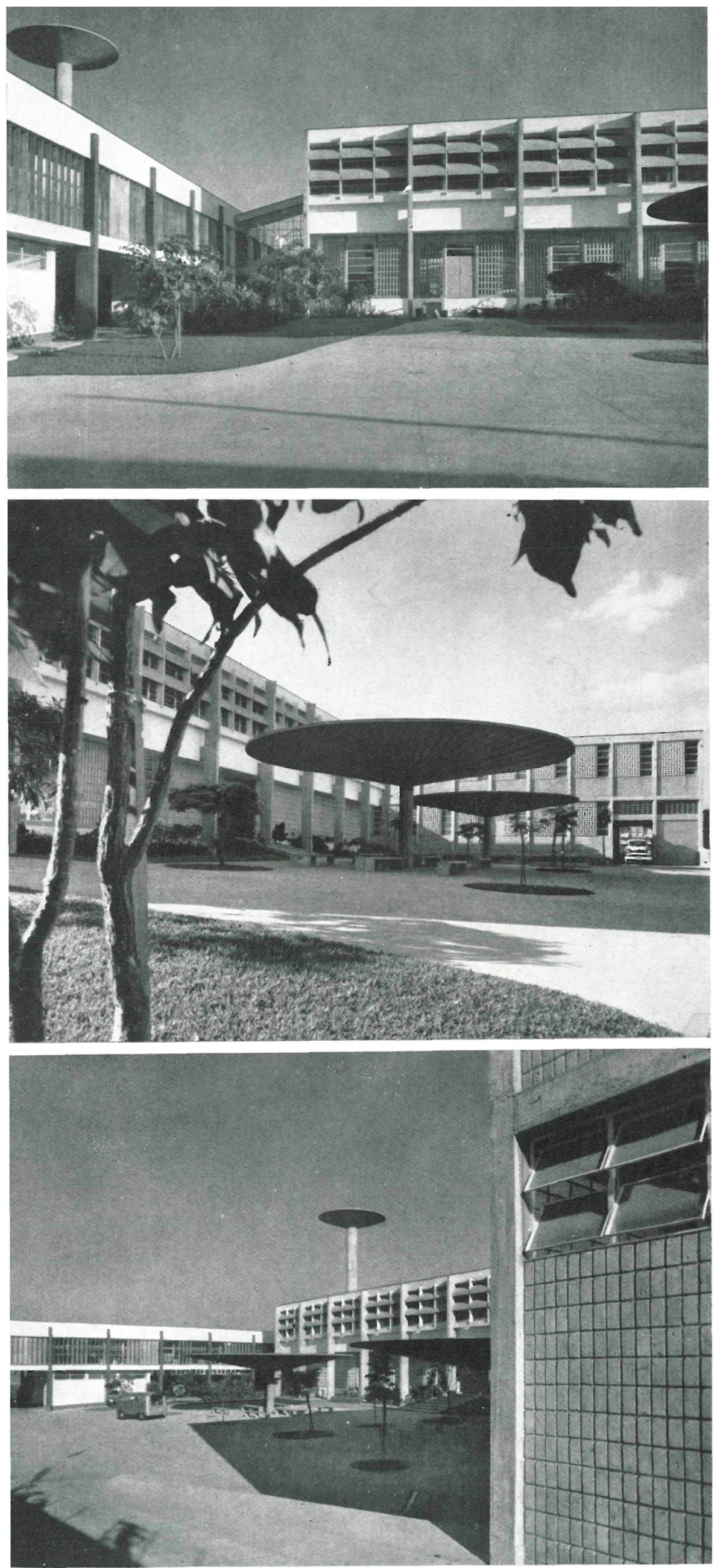

patio interior

Todos los edificios están unidos entre sí por medio de pórticos de hormigón armado, y en la fachada del edificio de la Administración, que da a la calle, se ha dispuesto una marquesina que protege la entrada. Las cubiertas de los edificios están todas construidas a base de chapas onduladas de fibrocemento. Las paredes son de ladrillo, materiales ligeros y cristal, mientras que los pavimentos interiores están recubiertos por piezas cerámicas. También en el interior existen varias escaleras, de unión entre los diferentes edificios y las distintas plantas, todas ellas construidas a base de hormigón.

Dada la naturaleza de la industria a que ha sido destinado el edificio se le ha dotado de instalaciones centrales de vapor, agua esterilizada, aire comprimido, vacío, oxígeno, gas y aire acondicionado. 


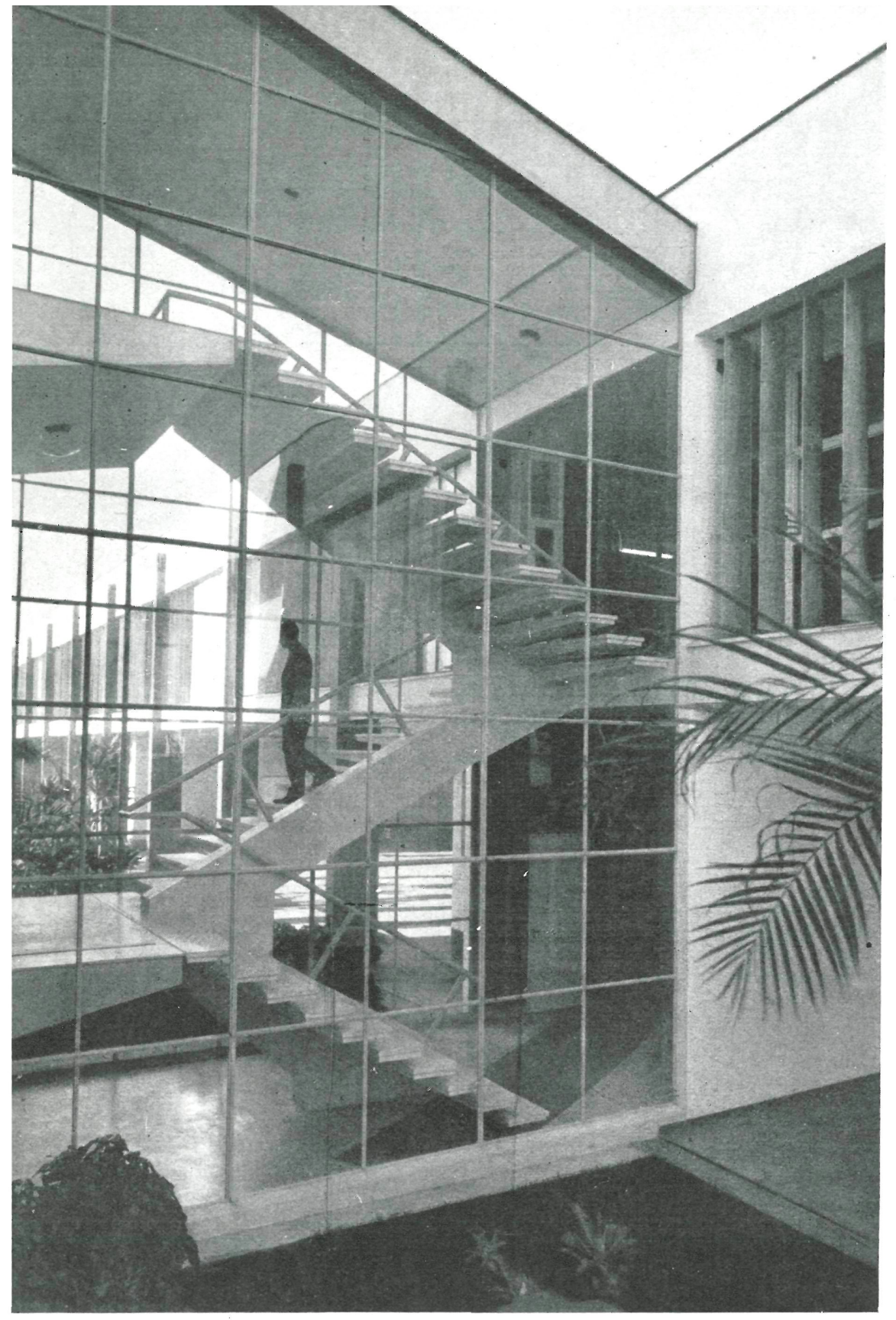

El hormigón visto, empleado aquí con profusión y crudeza, da un aspecto recio, sincero y expresivo a este complejo industrial en el que se ha logrado, además, una edificación de fácil entretenimiento y gran durabilidad.

Asimismo, las instalaciones de conducción interior han sido dotadas, donde era necesario, de tubos anticorrosivos de materia plástica.

Todas estas instalaciones hacen de es. ta moderna edificación una planta adecuada e inmejorablemente servida para la rápida e intensiva producción a que ha sido destinada.

Fotos: J. MOSCARD

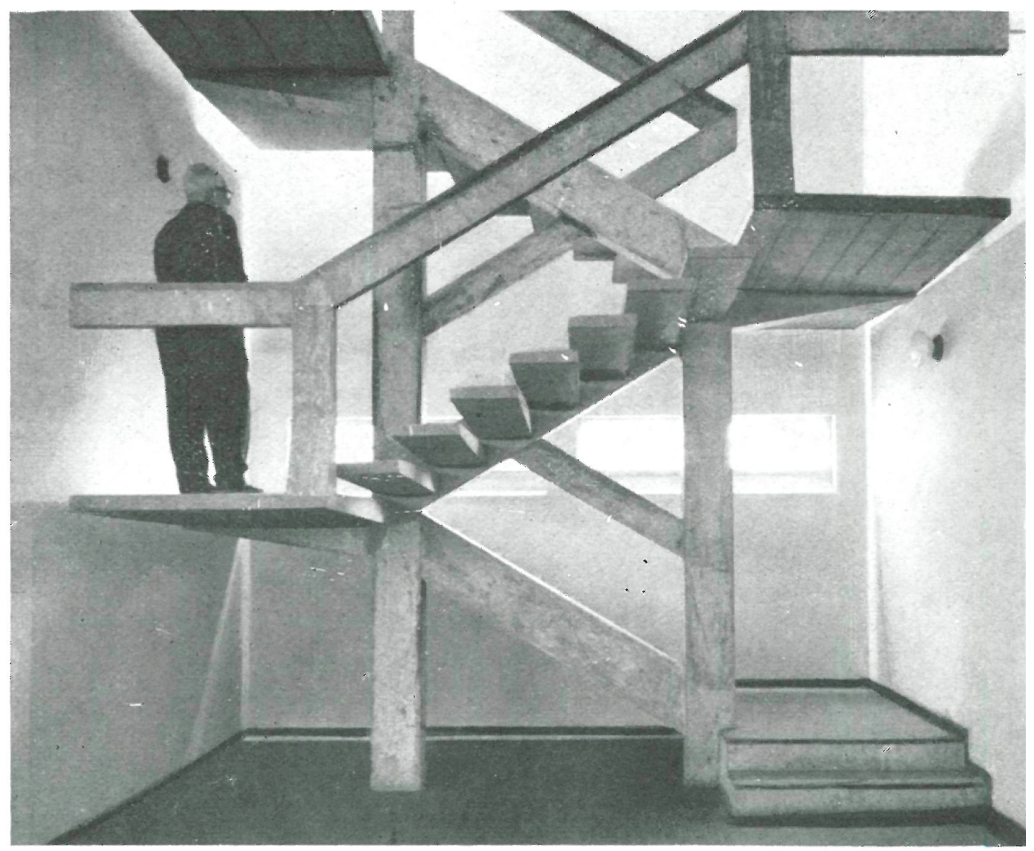




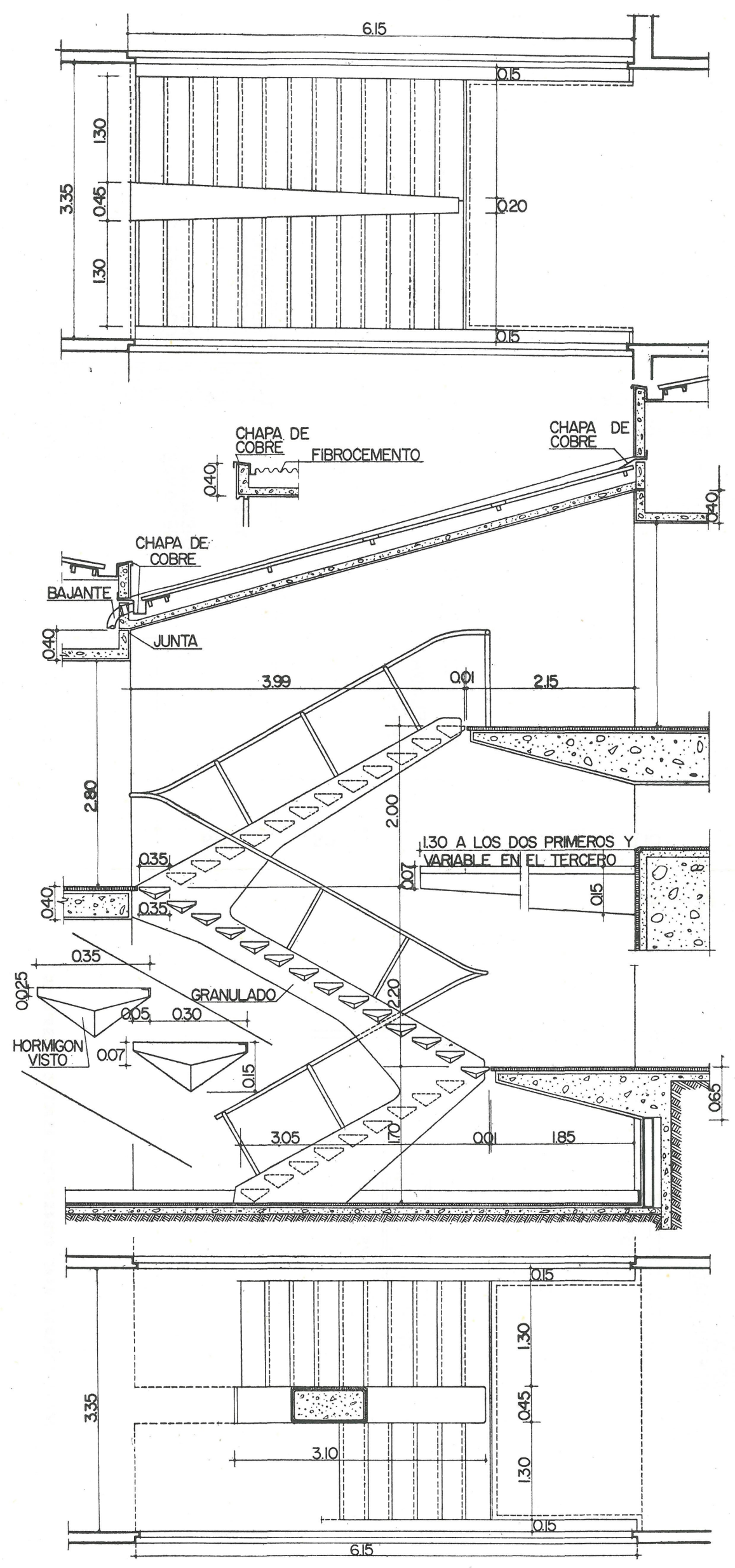

detalle de la escalera primcipall
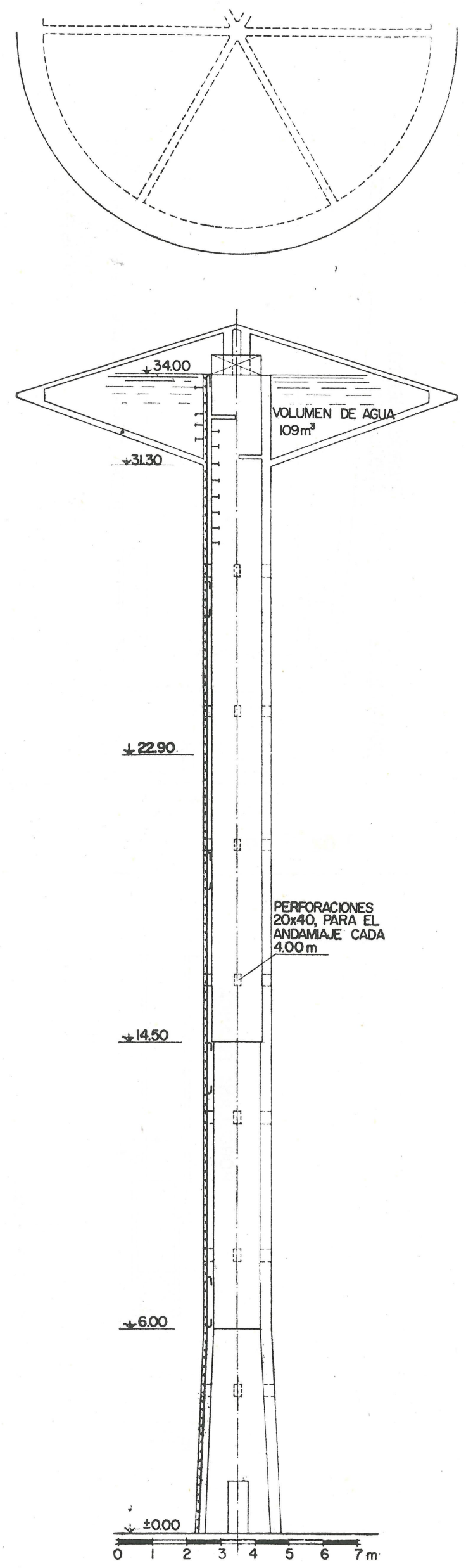

depósito de agumas 


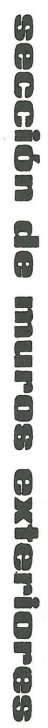
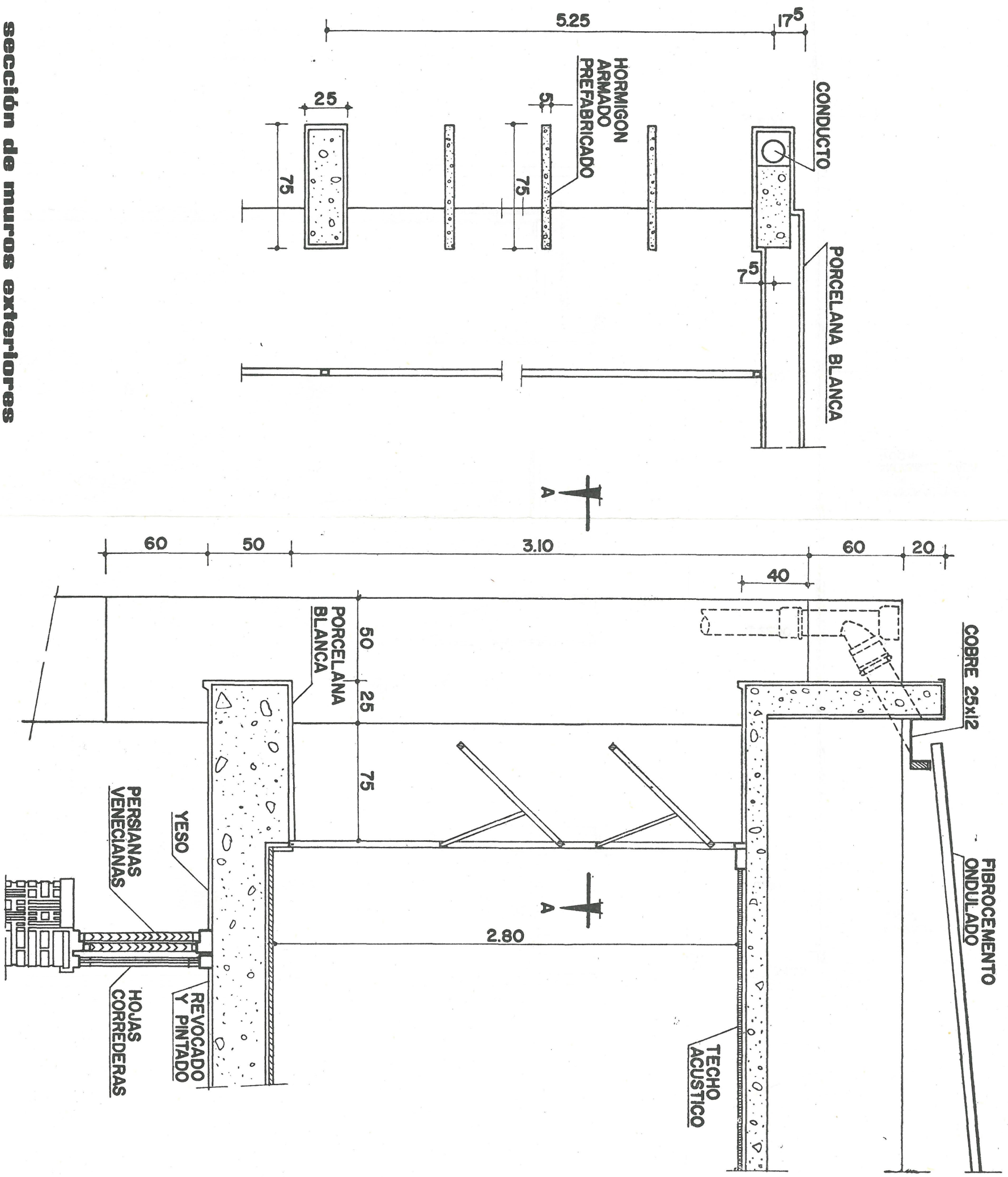